\title{
Performance of Leak Compensation in All-Age ICU Ventilators During Volume-Targeted Neonatal Ventilation: A Lung Model Study
}

\author{
Taiga Itagaki MD, Desmond J Bennett, Christopher T Chenelle, Daniel F Fisher MSc RRT, and \\ Robert M Kacmarek PhD RRT FAARC
}

\begin{abstract}
BACKGROUND: Volume-targeted ventilation is increasingly used in low birthweight infants because of the potential for reducing volutrauma and avoiding hypocapnea. However, it is not known what level of air leak is acceptable during neonatal volume-targeted ventilation when leak compensation is activated concurrently. METHODS: Four ICU ventilators (Servo-i, PB980, V500, and Avea) were compared in available invasive volume-targeted ventilation modes (pressure control continuous spontaneous ventilation [PC-CSV] and pressure control continuous mandatory ventilation [PC-CMV]). The Servo-i and PB980 were tested with (+) and without $(-)$ their proximal flow sensor. The V500 and Avea were tested with their proximal flow sensor as indicated by their manufacturers. An ASL 5000 lung model was used to simulate 4 neonatal scenarios (body weight $0.5,1,2$, and $4 \mathrm{~kg}$ ). The ASL 5000 was ventilated via an endotracheal tube with 3 different leaks. Two minutes of data were collected after each change in leak level, and the asynchrony index was calculated. Tidal volume $\left(V_{T}\right)$ before and after the change in leak was assessed. RESULTS: The differences in delivered $V_{T}$ between before and after the change in leak were within $\pm 5 \%$ in all scenarios with the PB980 ( $-/+)$ and V500. With the Servo-i $(-/+)$, baseline $V_{T}$ was $\geq 10 \%$ greater than set $V_{T}$ during PC-CSV, and delivered $V_{T}$ markedly changed with leak. The Avea demonstrated persistent high $\mathrm{V}_{\mathrm{T}}$ in all leak scenarios. Across all ventilators, the median asynchrony index was $1 \%$ (interquartile range $0-27 \%)$ in PC-CSV and $1.8 \%(0-45 \%)$ in PC-CMV. The median asynchrony index was significantly higher in the Servo-i $(-/+)$ than in the PB980 $(-/+)$ and V500 in 1 and 2 kg scenarios during PC-CSV and PC-CMV. CONCLUSIONS: The PB980 and V500 were the only ventilators to acclimate to all leak scenarios and achieve targeted $\mathrm{V}_{\mathrm{T}}$. Further clinical investigation is needed to validate the use of leak compensation during neonatal volume-targeted ventilation. Key words: neonates; mechanical ventilation; acute care ventilator; leak compensation; volume-targeted ventilation; patient-ventilator interaction. [Respir Care 2017;62(1):10-21. (C) 2017 Daedalus Enterprises]
\end{abstract}

\section{Introduction}

Traditionally, time-cycled, pressure-limited ventilation is used in neonatal ventilation due to the decelerating gas

\footnotetext{
The authors are affiliated with the Department of Respiratory Care, and Drs Itagaki and Kacmarek are affiliated with the Department of Anesthesia, Critical Care and Pain Medicine, Massachusetts General Hospital, Harvard Medical School, Boston, Massachusetts.

Supplementary material related to this paper is available at http:// www.rcjournal.com.

This study was funded in part by a research grant from Covidien. Dr Kacmarek has disclosed relationships with Covidien, Venner Medical, and Orange Medical. The other authors have disclosed no conflicts of interest.
}

flow pattern and the benefit of directly controlling peak inspiratory pressure. ${ }^{1}$ One disadvantage of pressure-limited ventilation is the variable tidal volumes that result from changes in lung compliance. Volume-targeted ventilation is a modification of pressure-limited ventilation that allows targeting of delivered tidal volume $\left(\mathrm{V}_{\mathrm{T}}\right)$ as a result of the development of sensitive and accurate flow sensors. ${ }^{2-4}$ Volume-targeted ventilation is increasingly used

\footnotetext{
Correspondence: Robert M Kacmarek PhD RRT FAARC, Department of Anesthesia, Critical Care and Pain Medicine, Massachusetts General Hospital, Harvard Medical School, 55 Fruit Street, Boston, MA 02114. E-mail: rkacmarek@mgh.harvard.edu.
}

DOI: $10.4187 /$ respcare. 05012 
in extremely low birthweight infants because of the potential for reducing volutrauma and avoiding hypocapnea. ${ }^{1,4-6}$ A Cochrane review concluded that volume-targeted ventilation resulted in significant reductions in the duration of ventilation, rate of pneumothorax, and severe intraventricular hemorrhage compared with infants ventilated using pressure-limited ventilation., 5,6

\section{See the Related Editorial on Page 135}

A major problem of mechanical ventilation in neonates is air leak because of the use of uncuffed endotracheal tubes (ETT). ${ }^{7}$ One of the major causes of triggering and cycling asynchrony is the presence of air leaks, which interferes with the ventilator's response to patients' spontaneous breathing efforts. ${ }^{8}$, Work of breathing and the duration of mechanical ventilation are directly affected by asynchronous patient-ventilator interactions. ${ }^{10,11}$ Also, an air leak potentially affects the operation of volume-targeted ventilation. Because expiratory $\mathrm{V}_{\mathrm{T}}$ measurement underestimates the actual delivered $\mathrm{V}_{\mathrm{T}}$ with large leaks, volume-targeted ventilation is generally recommended with ETT leaks up to 50\%.2-4 Recently, manufacturers have implemented leak compensation algorithms on the latest acute care ventilators to compensate for leaks, and these algorithms can be activated during volume-targeted ventilation modes of some ventilators. To date, it is unclear how accurately $\mathrm{V}_{\mathrm{T}}$ is delivered during neonatal volume-targeted ventilation when leak compensation is activated concurrently.

Previously, we assessed leak compensation and showed improved triggering and cycling synchronization in adult, ${ }^{12}$ pediatric, ${ }^{13}$ and neonatal ${ }^{14}$ settings; however, these studies were tested in conventional patient-triggered ventilation but not in volume-targeted ventilation. The aim of this bench study was to evaluate the capability of leak compensation of all-age ICU ventilators during neonatal volume-targeted ventilation in terms of (1) difference in delivered $\mathrm{V}_{\mathrm{T}}$ before and after leak was introduced and (2) prevention of asynchronous events. All-age ICU ventilators were the only ventilators evaluated in this study because our previous data indicated that all-age ventilators performed as well as neonatal ventilators. ${ }^{15}$

\section{Methods}

Four all-age ICU ventilators (Servo-i [Maquet, Wayne, New Jersey], PB980 [Covidien, Mansfield, Massachusetts], Evita Infinity V500 [Dräger, Telford, Pennsylvania], and Avea [CareFusion, San Diego, California]) (Table 1) were compared using an ASL 5000 lung simulator (version 3.5, IngMar Medical, Pittsburgh, Pennsylvania) with increasing and decreasing system leaks. Three-way stopcocks (Discofix, B. Braun Medical, Bethlehem, Pennsylvania)

\section{QUICK LOOK}

\section{Current knowledge}

Volume-targeted ventilation allows effective control of delivered tidal volume compared with conventional pressure-limited ventilation. Leaks affect delivered tidal volume accuracy and can cause trigger and cycling asynchrony.

\section{What this paper contributes to our knowledge}

Leak compensation performance demonstrated huge variations among all-age ICU ventilators during neonatal volume-targeted ventilation in terms of both accuracy of delivered tidal volume and prevention of patient-ventilator asynchronous events.

placed between an ETT and the lung simulator were used to create different leak levels (Fig. 1). The connection between the lung simulator and each ventilator was via the manufacturer's standard neonatal circuit or a standard neonatal circuit (Neonatal Breathing Circuit, Hudson RCITeleflex, Morrisville, North Carolina). Ventilators were studied with a dry circuit.

\section{Lung Model and Study Setup}

Four neonatal ventilation scenarios, with different lung sizes and mechanics estimated based on body weight $(0.5$, 1,2 , and $4 \mathrm{~kg}$ ) were simulated. Table 2 summarizes the settings of the ASL 5000 in each evaluated scenario. The following variables are listed for each scenario: inspiratory time with the time percentages of a single breath cycle for the pressure drop (inspiratory), pressure maintenance (hold), and relaxation (expiratory); the maximum inspiratory pressure drop and the airway occlusion pressure; and the breathing frequency, resistance, and compliance. Previous neonatal bench studies ${ }^{16-19}$ as well as clinical studies of lung function tests in preterm infants with severe respiratory failure $20-26$ were used to select compliance and resistance values for each model (compliance, $0.4-1.3 \mathrm{~mL} / \mathrm{cm}$ $\mathrm{H}_{2} \mathrm{O} / \mathrm{kg}$; resistance, $61-355 \mathrm{~cm} \mathrm{H}_{2} \mathrm{O} / \mathrm{L} / \mathrm{s}$ ). The pressure drop across each endotracheal tube as measured by a ventilator tester (PTS 2000, Mallinckrodt, Dublin, Ireland) and average peak flow achieved during the study were used to calculate the resistance across each endotracheal tube. Inspiratory efforts in children vary between waking and sleeping, ${ }^{27-29}$ especially in critically ill premature infants. ${ }^{16,30}$ Therefore, to account for this variability, we chose a smaller maximum inspiratory pressure drop than normally reported values in neonates. ${ }^{31}$

Uncuffed endotracheal tubes $(2.5-\mathrm{mm}$ internal diameter for $0.5 \mathrm{~kg}, 3.0-\mathrm{mm}$ internal diameter for $1 \mathrm{~kg}, 3.5-\mathrm{mm}$ 


\section{Leak Compensation During Neonatal Volume-Targeted Ventilation}

Table 1. Specifications for Neonatal Use of Mechanical Ventilators Tested

\begin{tabular}{|c|c|c|c|c|c|c|}
\hline \multirow{2}{*}{$\begin{array}{l}\text { Ventilator } \\
\text { (Software } \\
\text { Version) }\end{array}$} & \multirow{2}{*}{$\begin{array}{l}\text { Tidal Volume } \\
\text { Measurement }\end{array}$} & \multicolumn{2}{|c|}{$\begin{array}{c}\text { VTV Mode } \\
\text { (Manufacturer's Terminology) }\end{array}$} & \multirow{2}{*}{ Leak Compensation } & \multirow{2}{*}{$\begin{array}{l}\text { Flow Trigger } \\
\text { Sensitivity }\end{array}$} & \multirow{2}{*}{$\begin{array}{l}\text { Inspiratory } \\
\text { Rise Time }\end{array}$} \\
\hline & & PC-CSV & PC-CMV & & & \\
\hline $\begin{array}{l}\text { Servo-i } \\
(\mathrm{V} 6.01 .02)\end{array}$ & $\begin{array}{l}\text { At ventilator (optionally } \\
\text { at ETT) }\end{array}$ & $\begin{array}{l}\text { Volume support } \\
\text { (VS) }\end{array}$ & $\begin{array}{l}\text { Pressure-regulated } \\
\text { volume control } \\
\text { (PRVC) }\end{array}$ & $\begin{array}{l}20 \mathrm{~L} / \mathrm{min} \text {; } \\
\text { NIV: } 25 \mathrm{~L} / \mathrm{min} \text {; } \\
\text { nasal CPAP: } 15 \mathrm{~L} / \mathrm{min}\end{array}$ & $\begin{array}{l}0-100 \% \text { (fraction } \\
\text { of bias flow) }\end{array}$ & $0-0.2 \mathrm{~s}$ \\
\hline PB980 (K) & $\begin{array}{l}\text { At ventilator ( } 2 \text { inspiratory, } \\
1 \text { expiratory) (optionally at } \\
\text { ETT) }\end{array}$ & VS & $\mathrm{VC}+$ & $15 \mathrm{~L} / \mathrm{min}$ & $0.1-10 \mathrm{~L} / \mathrm{min}$ & $1-100 \%$ \\
\hline V500 (02.41) & At ETT & PS-VG & PC-VG & $30 \mathrm{~L} / \mathrm{min}$ & $0.2-15 \mathrm{~L} / \mathrm{min}$ & $0-2 \mathrm{~s}$ \\
\hline Avea (4.4) & At ETT & NA & VG & NI & $0.1-20 \mathrm{~L} / \mathrm{min}$ & $\begin{array}{l}1-9 \text { (relative } \\
\text { control) }\end{array}$ \\
\hline $\begin{array}{l}\text { VTV }=\text { volume-tar } \\
\text { PC-CSV }=\text { pressur } \\
\text { PC-CMV }=\text { pressur } \\
\text { ETT }=\text { endotrachea } \\
\text { NIV }=\text { noninvasive } \\
\text { VC }+=\text { volume co } \\
\text { PS-VG = pressure } \\
\text { PC-VG = pressure } \\
\text { VG }=\text { volume guar } \\
\text { NA }=\text { not available } \\
\text { NI }=\text { no informatio }\end{array}$ & $\begin{array}{l}\text { ted ventilation } \\
\text { control continuous spontaneous ventila } \\
\text { control continuous mandatory ventilat } \\
\text { tube } \\
\text { ventilation } \\
\text { trol plus } \\
\text { upport volume guarantee } \\
\text { ontrol volume guarantee } \\
\text { ntee }\end{array}$ & & & & & \\
\hline
\end{tabular}

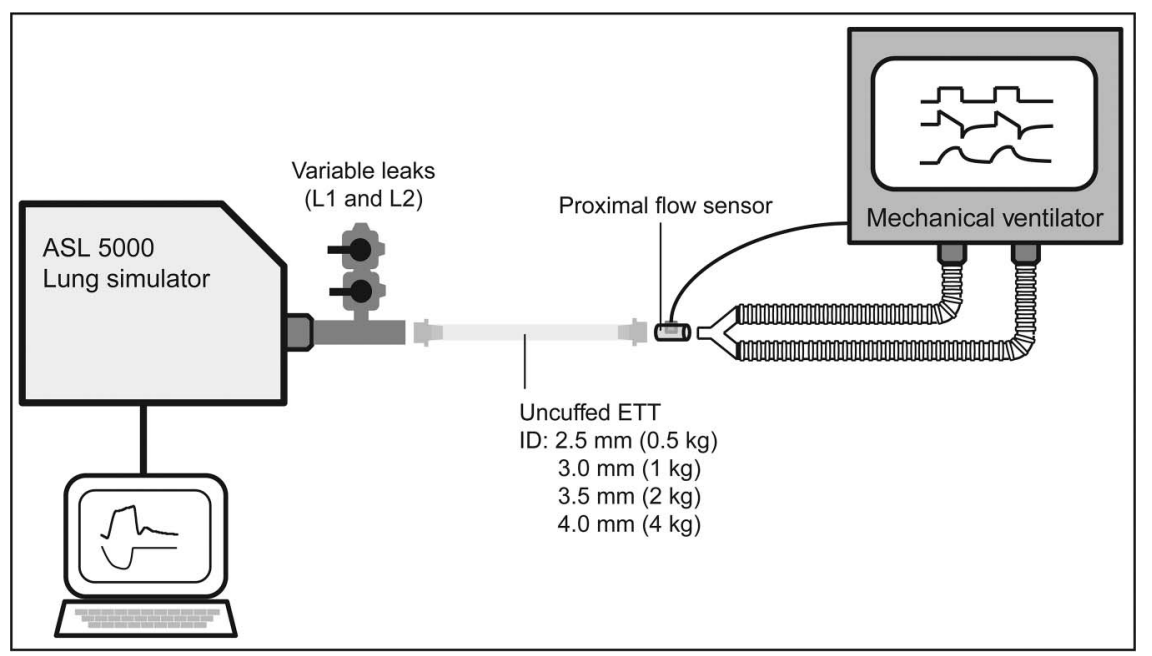

Fig. 1. Experimental setup. $\mathrm{L} 1=$ leak $1 ; \mathrm{L} 2=$ leak $2 ; \mathrm{ETT}=$ endotracheal tube; ID = inner diameter.

internal diameter for $2 \mathrm{~kg}$, and 4.0-mm internal diameter for $4 \mathrm{~kg}$ ) were used to directly affix the lung model to each ventilator. A baseline leak of $0 \mathrm{~L} / \mathrm{min}$ was established by vertically cutting the tip of each endotracheal tube and tightly connecting it to a common airway (Fig. 1). Two intentional leak levels (leak 1 and leak 2) were set to 0.1 and $0.2 \mathrm{~L} / \mathrm{min}$ (50 and $95 \%$ of minute ventilation) for 0.5 $\mathrm{kg}$; 0.2 and $0.4 \mathrm{~L} / \mathrm{min}$ (56 and $111 \%$ ) for $1 \mathrm{~kg} ; 0.3$ and $0.6 \mathrm{~L} / \mathrm{min}(50$ and $100 \%$ ) for $2 \mathrm{~kg}$; and 0.4 and $0.8 \mathrm{~L} / \mathrm{min}$ (42 and $83 \%$ ) for $4 \mathrm{~kg}$. Each leak volume was calibrated with the PTS 2000 connected between the ASL 5000 and the leak system at a constant negative airway pressure of
$5 \mathrm{~cm} \mathrm{H}_{2} \mathrm{O}$ maintained by the ASL 5000. Since our aim was to evaluate the maximum ability of the leak compensation algorithms of each ventilator, leak settings higher than clinically reported ${ }^{32,33}$ but within the claims of the manufacturers (Table 1) were selected. All 3 combinations of increasing leak change (baseline leak $\rightarrow$ leak 1 , baseline leak $\rightarrow$ leak 2 , and leak $1 \rightarrow$ leak 2 ) and all 3 combinations of decreasing leak change (leak $2 \rightarrow$ leak 1 , leak $2 \rightarrow$ baseline leak, and leak $1 \rightarrow$ baseline leak) were evaluated. All combinations of increasing and decreasing leaks were evaluated because in our previous studies ${ }^{12,13}$ we observed that the direction of the leak change and the magnitude of the 
Table 2. $\quad$ Lung Model Setup Used With ASL 5000

\begin{tabular}{|c|c|c|c|c|}
\hline \multirow{2}{*}{ Variables } & \multicolumn{4}{|c|}{ Scenario } \\
\hline & $0.5 \mathrm{~kg}$ & $1 \mathrm{~kg}$ & $2 \mathrm{~kg}$ & $4 \mathrm{~kg}$ \\
\hline ETT size, mm & 2.5 & 3.0 & 3.5 & 4.0 \\
\hline Frequency, breaths/min & 70 & 60 & 50 & 40 \\
\hline Compliance, $\mathrm{mL} / \mathrm{cm} \mathrm{H}_{2} \mathrm{O}$ & 0.5 & 1 & 2 & 5 \\
\hline $\mathrm{P}_{\max }, \mathrm{cm} \mathrm{H}_{2} \mathrm{O}$ & -3.0 & -4.0 & -5.0 & -6.0 \\
\hline Resistance (inspiratory/expiratory), $\mathrm{cm} \mathrm{H}_{2} \mathrm{O} / \mathrm{L} / \mathrm{s}$ & 200 & 150 & 100 & 50 \\
\hline Resistance of ETT used, $\mathrm{cm} \mathrm{H}_{2} \mathrm{O} / \mathrm{L} / \mathrm{s} *$ & 60.2 & 33.4 & 18.5 & 13.7 \\
\hline Estimated total respiratory resistance, $\mathrm{cm} \mathrm{H}_{2} \mathrm{O} / \mathrm{L} / \mathrm{s}^{* *}$ & 260.2 & 183.4 & 118.5 & 63.7 \\
\hline $\mathrm{P}_{0.1}, \mathrm{~cm} \mathrm{H}_{2} \mathrm{O}$ & -2.1 & -2.8 & -3.5 & -4.2 \\
\hline Unassisted tidal volume, $\mathrm{mL}$ & 0.9 & 3.2 & 7.8 & 23.2 \\
\hline Inspiratory time, $\mathrm{ms}$ & 250 & 300 & 350 & 400 \\
\hline Increase, $\%$ & 24.2 & 20.0 & 17.0 & 13.5 \\
\hline Hold, \% & 5.0 & 10.0 & 12.2 & 13.2 \\
\hline Release, $\%$ & 19.5 & 20.0 & 19.5 & 17.8 \\
\hline Pause, $\%$ & 0 & 0 & 0 & 0 \\
\hline $\mathrm{FRC}, \mathrm{mL}$ & 12.5 & 25 & 50 & 100 \\
\hline $\begin{array}{l}\text { * Values were calculated by using pressure drop across the tube and av } \\
* * \text { Estimated total respiratory resistance is equal to the sum of the lung } \\
\mathrm{P}_{\max }=\text { maximum inspiratory pressure drop } \\
\mathrm{P}_{0.1}=\text { airway occlusion pressure } 0.1 \mathrm{~s} \text { after the start of inspiratory flow } \\
\text { FRC = functional residual capacity } \\
\text { ETT = endotracheal tube }\end{array}$ & $\begin{array}{l}\text { during the } \\
\text { d resistanc }\end{array}$ & & & \\
\hline
\end{tabular}

leak change affected the ability of a ventilator to compensate for leaks. Before the study, the ASL 5000 was checked repeatedly for accuracy of tidal volume measurement by insufflating air from syringes of various volumes.

\section{Ventilator Settings}

All ventilators were tested in available volume-targeted pressure control continuous spontaneous ventilation (PC$\mathrm{CSV}$ ) and volume-targeted pressure control continuous mandatory ventilation (PC-CMV) modes. The Servo-i and PB980 were tested with $(+)$ and without $(-)$ their proximal flow sensor, since its use is optional. The V500 and Avea were always tested with the proximal flow sensor in accordance with the manufacturer's instructions. In both PC-CSV and PC-CMV, tidal volume $\left(\right.$ set $\mathrm{V}_{\mathrm{T}}$ ) was set at $6 \mathrm{~mL} / \mathrm{kg}$, and PEEP was set at $5 \mathrm{~cm} \mathrm{H}_{2} \mathrm{O}$. To ensure that our methods could be easily reproduced, flow trigger sensitivity was set to be as sensitive as possible while avoiding auto-triggering at baseline leak, and inspiratory rise time was set to the fastest setting in all ventilators tested. Leak compensation was always activated. The upper pressure limit was set at the maximum value possible. During PC-CSV, the termination criteria were set at a level to obtain total inspiratory time of the ventilator $\left(\mathrm{Ti}_{\text {vent }}\right.$; time from the start of effort to the moment the ventilator cycled from inspiration to exhalation) equal to $\pm 20 \%$ of the inspiratory time of the simulator $\left(\mathrm{Ti}_{\text {sim }}\right.$; increase $(\%)$ plus hold (\%) in the effort model). During PC-CMV, the ventilator frequency was set at $35,30,25$, and 20 breaths/min, and inspiratory time was set at 250, 300, 350, and 400 $\mathrm{ms} / \mathrm{min}$ for the $0.5,1,2$, and $4 \mathrm{~kg}$ models, respectively.

Apnea backup ventilation was activated with the apnea interval $20 \mathrm{~s}$. Since criteria of automatic return from backup ventilation differed between ventilators, if backup ventilation was activated, we immediately reset the ventilator and waited for spontaneous recovery.

\section{Data Collection and Evaluation}

Up to a 2-min waiting period was allowed for the simulator to consistently trigger the ventilator during baseline leak before data gathering. If triggering was established, all combinations of increasing and decreasing leaks were sequentially added to the system (baseline leak $\rightarrow$ leak $1 \rightarrow$ leak $2 \rightarrow$ leak $1 \rightarrow$ baseline leak $\rightarrow$ leak $2 \rightarrow$ baseline leak). After each change in leak level, we collected $2 \mathrm{~min}$ of data from the time of change in leak level. Delivered $\mathrm{V}_{\mathrm{T}}(\mathrm{mL})$, peak flow ( $\mathrm{L} / \mathrm{min})$, peak pressure $\left(\mathrm{cm} \mathrm{H}_{2} \mathrm{O}\right)$ and PEEP $\left(\mathrm{cm} \mathrm{H}_{2} \mathrm{O}\right)$ were recorded by the ASL 5000 for 2 min after each change in leak. The delivered $\mathrm{V}_{\mathrm{T}}$ before and after the change in leak (increase, baseline leak $\rightarrow$ leak 1 ; decrease, leak $1 \rightarrow$ baseline leak) was assessed as follows: (1) $\mathrm{V}_{\mathrm{T}}$ before the change (\%): average $\mathrm{V}_{\mathrm{T}}$ (\% of set $\mathrm{V}_{\mathrm{T}}$ ) of 5 consecutive, normally triggered breaths just before each change in leak; (2) $\mathrm{V}_{\mathrm{T}}$ after the change $(\%)$ : average $\mathrm{V}_{\mathrm{T}}\left(\%\right.$ of set $\left.\mathrm{V}_{\mathrm{T}}\right)$ of last 5 
consecutive, normally triggered breaths 2 min after each change in leak; (3) $\Delta \mathrm{V}_{\mathrm{T}}(\%)$ : average $\mathrm{V}_{\mathrm{T}}$ difference (\% of set $\mathrm{V}_{\mathrm{T}}$ ) between before and after the change in leak.

The global asynchrony index $7,34-36$ was calculated as follows: asynchrony index $=[$ (auto-triggering + doubletriggering + ineffective efforts + premature cycling + delayed cycling during $2 \mathrm{~min}$ )/(total simulated breaths + auto-triggering)] $\times 100$.

Synchronization was defined as triggering without autotriggering, double-triggering, ineffective efforts, premature cycling, and delayed cycling. Asynchrony events were detected by visual inspection of flow and airway pressure recordings. Asynchrony events were defined according to previous studies ${ }^{7,34-36:}$

- Auto-triggering: a cycle delivered by the ventilator in the absence of a signal generated by the lung simulator;

- Double-triggering: 2 ventilator-delivered cycles separated by a very short expiratory time occurring within a single inspiratory effort of the lung simulator;

- Ineffective efforts: inspiratory effort of the lung simulator not followed by a ventilator-delivered cycle;

- Delayed cycling: a cycle normally triggered by the ventilator but with $\mathrm{Ti}_{\text {vent }}$ greater than twice the $\mathrm{Ti}_{\text {sim }}$;

- Premature cycling: a cycle normally triggered by the ventilator but with $\mathrm{Ti}_{\text {vent }}$ less than one-half the $\mathrm{Ti}_{\text {sim }}$.

When backup ventilation operated, simulated breaths during backup ventilation were counted as ineffective efforts.

\section{Statistical Analysis}

Data were collected by the lung simulator's software (ASL 3.5), and each breath was manually analyzed to count asynchronous events by a single non-blinded observer. Results are expressed as mean \pm SD or medians with interquartile ranges depending on the parametric or non-parametric nature of the data distribution. A one-way analysis of variance with the Tukey honest significant difference post hoc test was used for parametric data, and the Kruskal-Wallis one-way analysis by ranks and the Dunn test for multiple comparisons were used for non-parametric data. Statistical analysis was conducted using R Statistical Software (R Foundation for Statistical Computing, Vienna, Austria). A value of $P<.05$ was considered statistically significant. We report only differences that were both statistically significant $(P<.05)$ and clinically important $(>10 \%)$.

\section{Results}

\section{Delivered $\mathbf{V}_{\mathbf{T}}$}

Tables 3 and 4 show delivered $\mathrm{V}_{\mathrm{T}}$ before and after the change in leak and $\Delta \mathrm{V}_{\mathrm{T}}$ during PC-CSV and PC-CMV. The Servo-i and Avea experienced significantly frequent asynchronous events at leak 2; thus, only $\mathrm{V}_{\mathrm{T}}$ data at baseline leak and leak 1 are shown in Tables 3 and 4 . Some $V_{T}$ data are not shown because 5 consecutive normally triggered breaths could not be obtained due to frequent asynchronous events with the specific leak.

In PC-CSV, mean delivered $\mathrm{V}_{\mathrm{T}}$ at the baseline leak (evaluating $\mathrm{V}_{\mathrm{T}}$ at baseline leak before changing to leak 1) was $\geq 10 \%$ greater than set $\mathrm{V}_{\mathrm{T}}$ in all scenarios with the Servo-i (-) and Servo-i (+) (Table 3). When leak increased and decreased, $\Delta \mathrm{V}_{\mathrm{T}}$ was statistically significant $(P<.01)$ and clinically important (absolute change $>10 \%)$ in the $2 \mathrm{~kg}$ scenarios with the Servo-i (-) and Servo-i (+) but not in $4 \mathrm{~kg} . \Delta \mathrm{V}_{\mathrm{T}}$ was consistent with the PB980 and V500 regardless of body weight, the use of a proximal flow sensor, and the direction of change in leak.

In PC-CMV, mean delivered $\mathrm{V}_{\mathrm{T}}$ at the baseline leak was generally within $\pm 10 \%$ of set $\mathrm{V}_{\mathrm{T}}$ in all ventilators (Table 4). However, delivered $V_{T}$ was $18 \%$ greater than set $V_{T}$ in the $4 \mathrm{~kg}$ scenario with the PB980 (-) and PB980 (+) and $15 \%$ smaller than set $\mathrm{V}_{\mathrm{T}}$ in the $4 \mathrm{~kg}$ scenario with the V500. $\Delta \mathrm{V}_{\mathrm{T}}$ was maintained within $\pm 5 \%$ in all scenarios with the PB980 (-), PB980 (+), and V500 when leak increased and decreased. In all scenarios with the Avea, both increase and decrease in leak caused statistically significant $(P<.01)$ and clinically important (absolute change $>10 \%)$ changes in $\mathrm{V}_{\mathrm{T}} . \Delta \mathrm{V}_{\mathrm{T}}$ was consistent regardless of body weight, the use of a proximal flow sensor, and the direction of change in leak with the PB980 (-), PB980 (+), V500, and Avea. The characteristics of acute change in delivered $\mathrm{V}_{\mathrm{T}}$ when leak increased and decreased are demonstrated in the supplementary materials at http://www.rcjournal.com.

\section{Performance of Leak Compensation on Synchrony}

All ventilators were triggered by inspiratory flow from the simulator in all tested conditions under the baseline leak. Across all ventilators, median asynchrony index was $1 \%$ (interquartile range $0-27 \%$ ) in PC-CSV (Fig. 2A) and $1.8 \%(0-45 \%)$ in PC-CMV (Fig. 2B). The asynchrony index varied widely, especially in scenarios where ventilators did not compensate for leaks at a higher level. There was no significant difference in asynchrony index between PC-CSV and PC-CMV in all tested ventilators. The asynchrony index tended to decrease but not significantly as body weight increased across all ventilators during PCCSV $(P=.36)$ and PC-CMV $(P=.47)$. In PC-CSV, median asynchrony index was significantly higher in the 


\section{Leak Compensation During Neonatal Volume-Targeted Ventilation}

Table 3. Delivered Tidal Volume Before and After the Change in Leak During Volume-Targeted Pressure Control Continuous Spontaneous Ventilation

\begin{tabular}{|c|c|c|c|c|c|}
\hline Tidal Volume & Servo-i (-) & Servo-i (+) & PB980 (-) & PB980 (+) & V500 \\
\hline \multicolumn{6}{|l|}{ Increase in leak (LB to L1) } \\
\hline \multicolumn{6}{|l|}{$4 \mathrm{~kg}\left(\right.$ set $\left.\mathrm{V}_{\mathrm{T}}=24 \mathrm{~mL}\right)$} \\
\hline $\mathrm{V}_{\mathrm{T}}$ before the change, $\%$ of set $\mathrm{V}_{\mathrm{T}}$ & $113.7 \pm 1.1$ & $112.0 \pm 1.3$ & $104.5 \pm 1.1$ & $99.8 \pm 0.5$ & $100.4 \pm 0.6$ \\
\hline $\mathrm{V}_{\mathrm{T}}$ after the change, $\%$ of set $\mathrm{V}_{\mathrm{T}}$ & $107.8 \pm 2.4$ & $107.2 \pm 0.3$ & $103.6 \pm 1.3$ & $98.9 \pm 2.7$ & $97.6 \pm 0.5$ \\
\hline$\Delta \mathrm{V}_{\mathrm{T}}, \%$ of set $\mathrm{V}_{\mathrm{T}}$ & -5.9 & -4.7 & -0.8 & -0.9 & -2.8 \\
\hline \multicolumn{6}{|l|}{$2 \mathrm{~kg}\left(\operatorname{set} \mathrm{V}_{\mathrm{T}}=12 \mathrm{~mL}\right)$} \\
\hline $\mathrm{V}_{\mathrm{T}}$ before the change, $\%$ of set $\mathrm{V}_{\mathrm{T}}$ & $111.9 \pm 1.0$ & $116.6 \pm 1.6$ & $99.5 \pm 1.2$ & $97.2 \pm 1.1$ & $93.3 \pm 0.8$ \\
\hline $\mathrm{V}_{\mathrm{T}}$ after the change, $\%$ of set $\mathrm{V}_{\mathrm{T}}$ & $85.4 \pm 1.2$ & $94.7 \pm 1.0$ & $97.6 \pm 2.3$ & $96.1 \pm 1.5$ & $94.0 \pm 0.2$ \\
\hline$\Delta \mathrm{V}_{\mathrm{T}}, \%$ of set $\mathrm{V}_{\mathrm{T}}$ & $-26.6^{*}$ & $-21.9^{*}$ & -1.9 & -1.1 & 0.8 \\
\hline \multicolumn{6}{|l|}{$1 \mathrm{~kg}\left(\mathrm{set} \mathrm{V}_{\mathrm{T}}=6 \mathrm{~mL}\right)$} \\
\hline $\mathrm{V}_{\mathrm{T}}$ before the change, $\%$ of set $\mathrm{V}_{\mathrm{T}}$ & $112.6 \pm 3.5$ & $113.7 \pm 1.4$ & $98.3 \pm 3.6$ & $97.6 \pm 3.5$ & $102.0 \pm 1.0$ \\
\hline $\mathrm{V}_{\mathrm{T}}$ after the change, $\%$ of set $\mathrm{V}_{\mathrm{T}}$ & ND & ND & $97.7 \pm 3.5$ & $96.1 \pm 3.3$ & $99.5 \pm 2.6$ \\
\hline$\Delta \mathrm{V}_{\mathrm{T}}, \%$ of set $\mathrm{V}_{\mathrm{T}}$ & & & -0.7 & -1.4 & -2.5 \\
\hline \multicolumn{6}{|l|}{$0.5 \mathrm{~kg}\left(\mathrm{set} \mathrm{V}_{\mathrm{T}}=3 \mathrm{~mL}\right)$} \\
\hline $\mathrm{V}_{\mathrm{T}}$ before the change, $\%$ of set $\mathrm{V}_{\mathrm{T}}$ & $131.5 \pm 1.2$ & $133.2 \pm 3.8$ & $95.1 \pm 0.6$ & $91.9 \pm 1.8$ & $104.3 \pm 1.4$ \\
\hline $\mathrm{V}_{\mathrm{T}}$ after the change, $\%$ of set $\mathrm{V}_{\mathrm{T}}$ & ND & ND & $97.5 \pm 1.1$ & $94.7 \pm 0.8$ & $113.7 \pm 8.5$ \\
\hline$\Delta \mathrm{V}_{\mathrm{T}}, \%$ of set $\mathrm{V}_{\mathrm{T}}$ & & & 2.4 & 2.8 & 9.3 \\
\hline \multicolumn{6}{|l|}{ Decrease in leak (L1 to LB) } \\
\hline \multicolumn{6}{|l|}{$4 \mathrm{~kg}\left(\operatorname{set} \mathrm{V}_{\mathrm{T}}=24 \mathrm{~mL}\right)$} \\
\hline $\mathrm{V}_{\mathrm{T}}$ before the change, $\%$ of set $\mathrm{V}_{\mathrm{T}}$ & $112.6 \pm 1.6$ & $104.9 \pm 0.8$ & $106.0 \pm 0.2$ & $98.8 \pm 2.6$ & $97.8 \pm 1.1$ \\
\hline $\mathrm{V}_{\mathrm{T}}$ after the change, $\%$ of set $\mathrm{V}_{\mathrm{T}}$ & $110.2 \pm 1.4$ & $108.9 \pm 0.5$ & $106.5 \pm 0.4$ & $100.0 \pm 0.7$ & $95.2 \pm 0.5$ \\
\hline$\Delta \mathrm{V}_{\mathrm{T}}, \%$ of set $\mathrm{V}_{\mathrm{T}}$ & -2.4 & 4.1 & 0.5 & 1.2 & -2.6 \\
\hline \multicolumn{6}{|l|}{$2 \mathrm{~kg}\left(\operatorname{set} \mathrm{V}_{\mathrm{T}}=12 \mathrm{~mL}\right)$} \\
\hline $\mathrm{V}_{\mathrm{T}}$ before the change, $\%$ of set $\mathrm{V}_{\mathrm{T}}$ & $87.4 \pm 1.5$ & $85.1 \pm 0.5$ & $96.8 \pm 1.6$ & $95.3 \pm 0.9$ & $94.3 \pm 1.2$ \\
\hline $\mathrm{V}_{\mathrm{T}}$ after the change, $\%$ of set $\mathrm{V}_{\mathrm{T}}$ & $107.7 \pm 1.6$ & $109.0 \pm 0.7$ & $97.4 \pm 1.8$ & $96.8 \pm 2.2$ & $94.3 \pm 1.4$ \\
\hline$\Delta \mathrm{V}_{\mathrm{T}}, \%$ of set $\mathrm{V}_{\mathrm{T}}$ & $20.3^{*}$ & $23.8^{*}$ & 0.6 & 1.5 & 0.0 \\
\hline \multicolumn{6}{|l|}{$1 \mathrm{~kg}\left(\right.$ set $\left.\mathrm{V}_{\mathrm{T}}=6 \mathrm{~mL}\right)$} \\
\hline $\mathrm{V}_{\mathrm{T}}$ before the change, $\%$ of set $\mathrm{V}_{\mathrm{T}}$ & ND & ND & $98.3 \pm 3.2$ & $98.5 \pm 1.6$ & $98.0 \pm 1.1$ \\
\hline $\mathrm{V}_{\mathrm{T}}$ after the change, $\%$ of set $\mathrm{V}_{\mathrm{T}}$ & $129.3 \pm 3.0$ & $114.7 \pm 1.5$ & $100.2 \pm 3.6$ & $97.9 \pm 5.0$ & $101.8 \pm 1.2$ \\
\hline$\Delta \mathrm{V}_{\mathrm{T}}, \%$ of set $\mathrm{V}_{\mathrm{T}}$ & & & 1.9 & -0.5 & 3.8 \\
\hline \multicolumn{6}{|l|}{$0.5 \mathrm{~kg}\left(\right.$ set $\left.\mathrm{V}_{\mathrm{T}}=3 \mathrm{~mL}\right)$} \\
\hline $\mathrm{V}_{\mathrm{T}}$ before the change, $\%$ of set $\mathrm{V}_{\mathrm{T}}$ & ND & ND & $96.7 \pm 1.1$ & $94.5 \pm 0.3$ & $111.5 \pm 4.1$ \\
\hline $\mathrm{V}_{\mathrm{T}}$ after the change, $\%$ of set $\mathrm{V}_{\mathrm{T}}$ & $132.9 \pm 4.4$ & $133.9 \pm 3.5$ & $96.1 \pm 0.7$ & $94.0 \pm 1.4$ & $104.7 \pm 1.6$ \\
\hline$\Delta \mathrm{V}_{\mathrm{T}}, \%$ of set $\mathrm{V}_{\mathrm{T}}$ & & & -0.8 & -0.5 & -6.9 \\
\hline \multicolumn{6}{|c|}{$\begin{array}{l}\text { Data are mean } \pm \mathrm{SD} \text {. }(+) \text { with Servo-i and } \mathrm{PB} 980 \text { indicates that the proximal flow sensor was used; }(-) \text { indicates no proximal flow sensor. } \Delta \mathrm{V}_{\mathrm{T}}(\%) \text { is the } \mathrm{V}_{\mathrm{T}} \text { after the change in leak minus } \mathrm{V}_{\mathrm{T}} \\
\text { before the change in leak. The absence of data (ND) indicates that } 5 \text { consecutive synchronous breaths could not be obtained. } \\
\left.* \text { Differences versus } \mathrm{V}_{\mathrm{T}} \text { before the change were statistically significant }(P<.05) \text { and clinically important (absolute change }>10 \%\right) \text {. } \\
\mathrm{LB}=\text { baseline leak; } \mathrm{L} 1=\text { leak } 1 ; \mathrm{ND}=\text { no data }\end{array}$} \\
\hline
\end{tabular}

Servo-i (-) and Servo-i (+) than the PB980 (-), PB980 $(+)$, and V500 in $0.5,1$, and $2 \mathrm{~kg}$ scenarios except for the $0.5 \mathrm{~kg}$ scenario versus the V500 $(P<.05$ for all comparisons, Fig. 2A). In PC-CMV, median asynchrony index was significantly higher in the Servo-i $(-)$ and Servo-i $(+)$ than in the PB980 (-), PB980 (+), and V500 in the 1,2 , and $4 \mathrm{~kg}$ scenarios and also higher than the Avea in the $4 \mathrm{~kg}$ scenario $(P<.05$ for all comparisons, Fig. 2B). With the Servo-i and PB980, there was no relationship between asynchrony index and the use of a proximal flow sensor in any scenarios during both modes.

Across all ventilators, asynchrony index increased with leak in PC-CSV $(P<.05$, Fig. 3A) and tended to increase but not significantly with leak in PC-CMV $(P=.064$, Fig. 3B).
In PC-CSV, asynchrony index was significantly higher with the Servo-i ( - ) and Servo-i $(+)$ than the other ventilators at the leak 1 and leak 2 levels (Fig. 3A). In PC-CMV, the asynchrony index was significantly higher with the Servo-i $(-)$, Servo-i (+), and Avea than the other ventilators at the leak 1 and leak 2 levels except for the Avea at leak 1 (Fig. 3B).

\section{Cause of Asynchrony}

Delayed cycling was seen only during PC-CMV, and there was no premature cycling in any tested conditions. Auto-triggering was the most common cause of asynchrony during PC-CSV, and delayed cycling was the most com- 


\section{Leak Compensation During Neonatal Volume-Targeted Ventilation}

Table 4. Delivered Tidal Volume Before and After the Change in Leak During Volume-Targeted Pressure Control Continuous Mandatory Ventilation

\begin{tabular}{|c|c|c|c|c|c|c|}
\hline & Servo-i $(-)$ & Servo-i (+) & PB980 (-) & PB980 (+) & V500 & Avea \\
\hline \multicolumn{7}{|l|}{ Increase in leak (LB to $\mathrm{L} 1)$} \\
\hline \multicolumn{7}{|l|}{$4 \mathrm{~kg}\left(\right.$ set $\left.\mathrm{V}_{\mathrm{T}}=24 \mathrm{~mL}\right)$} \\
\hline $\mathrm{V}_{\mathrm{T}}$ before the change, $\%$ of set $\mathrm{V}_{\mathrm{T}}$ & $110.7 \pm 0.6$ & $109.7 \pm 0.5$ & $120.5 \pm 0.1$ & $118.6 \pm 0.1$ & $85.5 \pm 0.9$ & $101.9 \pm 0.1$ \\
\hline $\begin{array}{l}\mathrm{V}_{\mathrm{T}} \text { after the change, } \% \text { of set } \mathrm{V}_{\mathrm{T}} \\
\Delta \mathrm{V}_{\mathrm{T}}, \% \text { of set } \mathrm{V}_{\mathrm{T}}\end{array}$ & ND & ND & $\begin{array}{l}116.6 \pm 0.1 \\
-3.9\end{array}$ & $\begin{array}{l}114.6 \pm 0.1 \\
-4.0\end{array}$ & $\begin{array}{c}89.2 \pm 1.9 \\
3.7\end{array}$ & $\begin{array}{c}122.4 \pm 0.2 \\
20.6^{*}\end{array}$ \\
\hline \multicolumn{7}{|l|}{$2 \mathrm{~kg}\left(\mathrm{set} \mathrm{V}_{\mathrm{T}}=12 \mathrm{~mL}\right)$} \\
\hline $\mathrm{V}_{\mathrm{T}}$ before the change, $\%$ of set $\mathrm{V}_{\mathrm{T}}$ & $104.8 \pm 0.7$ & $104.8 \pm 0.6$ & $102.3 \pm 0.7$ & $100.6 \pm 1.3$ & $96.5 \pm 0.7$ & $96.1 \pm 0.8$ \\
\hline $\begin{array}{l}\mathrm{V}_{\mathrm{T}} \text { after the change, } \% \text { of set } \mathrm{V}_{\mathrm{T}} \\
\Delta \mathrm{V}_{\mathrm{T}}, \% \text { of set } \mathrm{V}_{\mathrm{T}}\end{array}$ & ND & ND & $\begin{array}{l}100.9 \pm 0.5 \\
\quad-1.4\end{array}$ & $\begin{array}{l}98.5 \pm 0.5 \\
-2.2\end{array}$ & $\begin{array}{l}94.2 \pm 0.4 \\
-2.3\end{array}$ & $\begin{array}{c}123.3 \pm 0.5 \\
27.2^{*}\end{array}$ \\
\hline \multicolumn{7}{|l|}{$1 \mathrm{~kg}\left(\mathrm{set} \mathrm{V}_{\mathrm{T}}=6 \mathrm{~mL}\right)$} \\
\hline $\mathrm{V}_{\mathrm{T}}$ before the change, $\%$ of set $\mathrm{V}_{\mathrm{T}}$ & $107.9 \pm 1.0$ & $107.7 \pm 0.6$ & $98.5 \pm 0.6$ & $102.9 \pm 1.2$ & $96.1 \pm 2.1$ & $100.7 \pm 1.8$ \\
\hline $\mathrm{V}_{\mathrm{T}}$ after the change, $\%$ of set $\mathrm{V}_{\mathrm{T}}$ & ND & $97.8 \pm 3.9$ & $97.4 \pm 1.1$ & $101.1 \pm 0.4$ & $97.6 \pm 1.3$ & $137.7 \pm 7.2$ \\
\hline $\begin{array}{c}\Delta \mathrm{V}_{\mathrm{T}}, \% \text { of set } \mathrm{V}_{\mathrm{T}} \\
0.5 \mathrm{~kg}\left(\text { set } \mathrm{V}_{\mathrm{T}}=3 \mathrm{~mL}\right)\end{array}$ & & -9.9 & -1.1 & -1.8 & 1.6 & $37.0^{*}$ \\
\hline $\mathrm{V}_{\mathrm{T}}$ before the change, $\%$ of set $\mathrm{V}_{\mathrm{T}}$ & $109.7 \pm 3.7$ & $101.1 \pm 5.1$ & $92.7 \pm 1.0$ & $91.7 \pm 0.9$ & $104.5 \pm 5.0$ & $93.5 \pm 0.6$ \\
\hline $\mathrm{V}_{\mathrm{T}}$ after the change, $\%$ of set $\mathrm{V}_{\mathrm{T}}$ & ND & ND & $94.7 \pm 1.7$ & $94.8 \pm 0.9$ & $106.0 \pm 1.6$ & $127.3 \pm 7.0$ \\
\hline$\Delta \mathrm{V}_{\mathrm{T}}, \%$ of set $\mathrm{V}_{\mathrm{T}}$ & & & 2.0 & 3.1 & 1.5 & $33.8 *$ \\
\hline \multicolumn{7}{|l|}{ Decrease in leak (L1 to LB) } \\
\hline \multicolumn{7}{|l|}{$4 \mathrm{~kg}\left(\right.$ set $\left.\mathrm{V}_{\mathrm{T}}=24 \mathrm{~mL}\right)$} \\
\hline $\mathrm{V}_{\mathrm{T}}$ before the change, $\%$ of set $\mathrm{V}_{\mathrm{T}}$ & ND & ND & $116.6 \pm 0.1$ & $113.7 \pm 0.1$ & $90.0 \pm 0.7$ & $122.9 \pm 0.3$ \\
\hline $\mathrm{V}_{\mathrm{T}}$ after the change, $\%$ of set $\mathrm{V}_{\mathrm{T}}$ & $109.1 \pm 0.3$ & $122.2 \pm 0.8$ & $119.6 \pm 0.1$ & $117.7 \pm 0.2$ & $87.8 \pm 0.6$ & $101.8 \pm 0.5$ \\
\hline$\Delta \mathrm{V}_{\mathrm{T}}, \%$ of set $\mathrm{V}_{\mathrm{T}}$ & & & 3.0 & 4.1 & -2.2 & $-21.1^{*}$ \\
\hline \multicolumn{7}{|l|}{$2 \mathrm{~kg}\left(\operatorname{set} \mathrm{V}_{\mathrm{T}}=12 \mathrm{~mL}\right)$} \\
\hline $\mathrm{V}_{\mathrm{T}}$ before the change, $\%$ of set $\mathrm{V}_{\mathrm{T}}$ & ND & ND & $101.0 \pm 0.2$ & $98.5 \pm 0.7$ & $93.6 \pm 0.4$ & $124.0 \pm 0.6$ \\
\hline $\mathrm{V}_{\mathrm{T}}$ after the change, $\%$ of set $\mathrm{V}_{\mathrm{T}}$ & $106.8 \pm 0.3$ & $107.3 \pm 0.5$ & $102.2 \pm 0.6$ & $101.1 \pm 0.2$ & $94.0 \pm 0.7$ & $96.6 \pm 0.8$ \\
\hline$\Delta \mathrm{V}_{\mathrm{T}}, \%$ of set $\mathrm{V}_{\mathrm{T}}$ & & & 1.3 & 2.6 & 0.4 & $-27.4^{*}$ \\
\hline \multicolumn{7}{|l|}{$1 \mathrm{~kg}\left(\right.$ set $\left.\mathrm{V}_{\mathrm{T}}=6 \mathrm{~mL}\right)$} \\
\hline $\mathrm{V}_{\mathrm{T}}$ before the change, $\%$ of set $\mathrm{V}_{\mathrm{T}}$ & $101.7 \pm 1.3$ & $96.5 \pm 3.1$ & $96.2 \pm 0.9$ & $101.1 \pm 0.6$ & $98.1 \pm 1.0$ & $137.9 \pm 1.9$ \\
\hline $\mathrm{V}_{\mathrm{T}}$ after the change, $\%$ of set $\mathrm{V}_{\mathrm{T}}$ & $108.4 \pm 1.1$ & $108.5 \pm 0.8$ & $98.5 \pm 0.8$ & $102.5 \pm 0.9$ & $102.8 \pm 1.1$ & $101.4 \pm 1.1$ \\
\hline$\Delta \mathrm{V}_{\mathrm{T}}, \%$ of set $\mathrm{V}_{\mathrm{T}}$ & 6.7 & $12.0^{*}$ & 2.4 & 1.4 & 4.7 & $-36.5^{*}$ \\
\hline \multicolumn{7}{|l|}{$0.5 \mathrm{~kg}\left(\mathrm{set} \mathrm{V}_{\mathrm{T}}=3 \mathrm{~mL}\right)$} \\
\hline $\mathrm{V}_{\mathrm{T}}$ before the change, $\%$ of set $\mathrm{V}_{\mathrm{T}}$ & ND & ND & $94.5 \pm 1.8$ & $95.2 \pm 0.7$ & $107.1 \pm 2.3$ & $125.0 \pm 9.7$ \\
\hline $\mathrm{V}_{\mathrm{T}}$ after the change, $\%$ of set $\mathrm{V}_{\mathrm{T}}$ & $110.9 \pm 3.7$ & $105.1 \pm 7.4$ & $94.5 \pm 1.0$ & $91.1 \pm 1.0$ & $104.9 \pm 1.6$ & $100.4 \pm 5.4$ \\
\hline$\Delta \mathrm{V}_{\mathrm{T}}, \%$ of set $\mathrm{V}_{\mathrm{T}}$ & & & 0.1 & -4.1 & -2.2 & $-24.6^{*}$ \\
\hline \multicolumn{7}{|c|}{$\begin{array}{l}\text { Data are mean } \pm \mathrm{SD} \text {. }(+) \text { with Servo-i and PB980 indicates that the proximal flow sensor was used; }(-) \text { indicates no proximal flow sensor. } \Delta \mathrm{V}_{\mathrm{T}}(\%) \text { is the } \mathrm{V}_{\mathrm{T}} \text { after the change in leak minus } \mathrm{V}_{\mathrm{T}} \\
\text { before the change in leak. The absence of data }(\mathrm{ND}) \text { indicates that } 5 \text { consecutive synchronous breaths could not be obtained. } \\
\left.\text { * Differences versus } \mathrm{V}_{\mathrm{T}} \text { before the change were statistically significant }(P<.05) \text { and clinically important (absolute change }>10 \%\right) \\
\mathrm{LB}=\text { baseline leak; } \mathrm{L} 1=\text { leak } 1 ; \mathrm{ND}=\text { no data }\end{array}$} \\
\hline
\end{tabular}

mon cause of asynchrony during PC-CMV (Fig. 4, A and $\mathrm{B})$. In PC-CSV, the incidence of both auto-triggering and double-triggering was significantly higher with the Servo-i (-) (auto-triggering, 26.3\%; double-triggering, 12.4\%) and Servo-i (+) (auto-triggering, 26.8\%; double-triggering, $11.6 \%$ ) when compared with the V500 for auto-triggering (0.3\%, $P<.001$ for all comparisons) and PB980 ( - ) for double-triggering $(0 \%, P<.005$ for all comparisons) (Fig. 4A). In PC-CMV, the incidence of auto-triggering was significantly higher with the Servo-i (-) (23.1\%), Servo-i (+) $(22.1 \%)$, and Avea $(21.1 \%)$ when compared with the V500, which had the lowest rates of auto-triggering $(0.3 \%$, $P<.05$ for all comparisons) (Fig. 4B). There was no significant difference in the rate of delayed cycling.

\section{Peak Flow and Peak Pressure During Variable Leak}

Across all body weights, peak flow and peak pressure significantly increased as the leak increased only with the Avea, and PEEP did not demonstrate a relationship with leak level in any of the tested ventilators. Data are shown in the supplementary materials.

\section{Discussion}

The main findings of this study are as follows: (1) the PB980, V500, and Avea showed acceptable baseline $V_{T}$ within $\pm 10 \%$ of set $\mathrm{V}_{\mathrm{T}}$ in almost all tested conditions; (2) the overall effect of leak on delivered $V_{T}$ accuracy was 

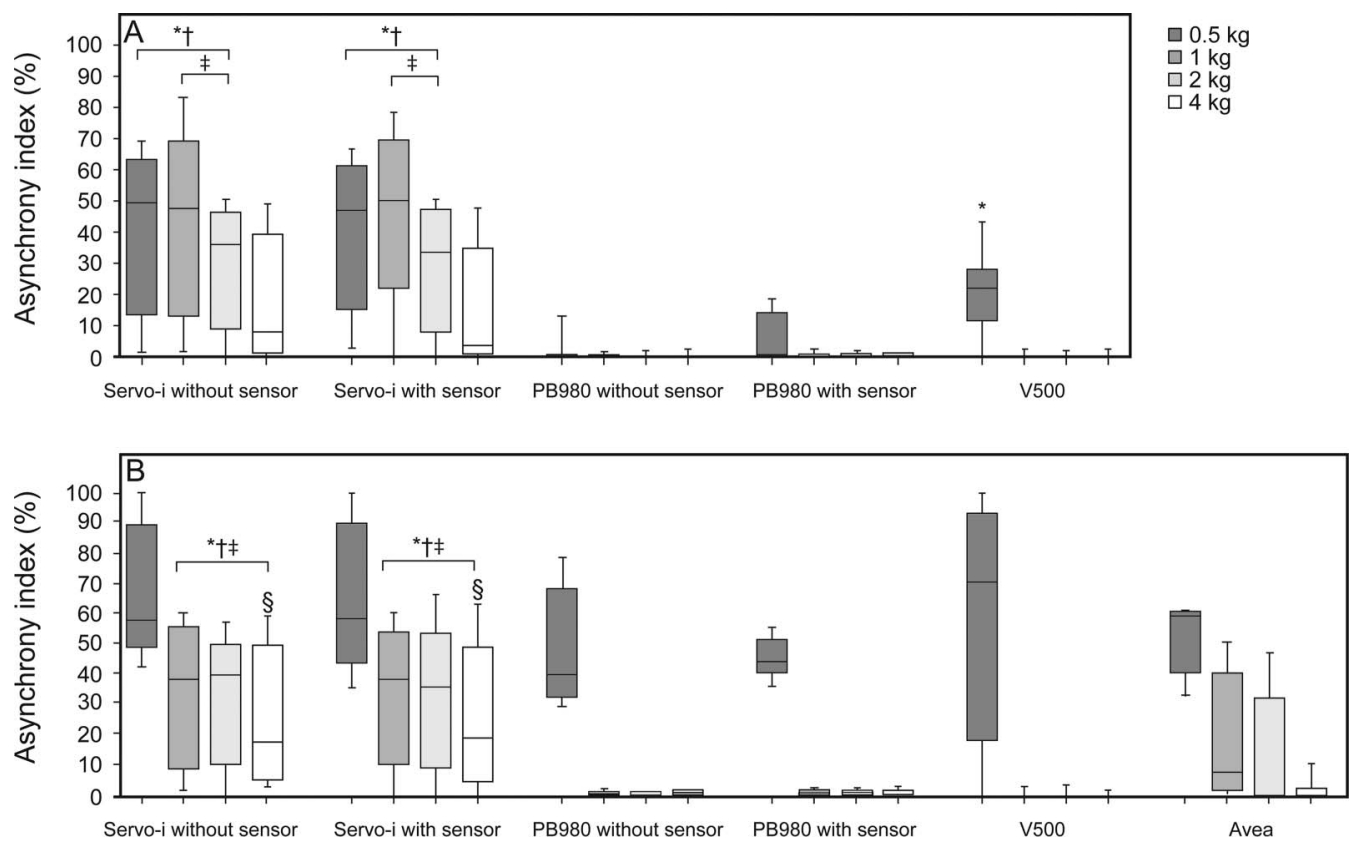

Fig. 2. Asynchrony index (\%) during volume-targeted ventilation relative to body weight. A: Volume-targeted pressure control continuous spontaneous ventilation. B: Volume-targeted pressure control continuous mandatory ventilation. Each box represents the interquartile range, with the median value shown as a horizontal line in the box. Error bars represent the maximum and minimum values. Data across all leak levels were compared between ventilators at each body weight. The Servo-i and PB980 were used with and without the proximal flow sensor. ${ }^{*}=P<.05$ vs PB980 without sensor, $\dagger=P<.05$ vs PB980 with sensor, $\ddagger=P<.05$ vs V500; all were clinically significant $(>10 \%)$.
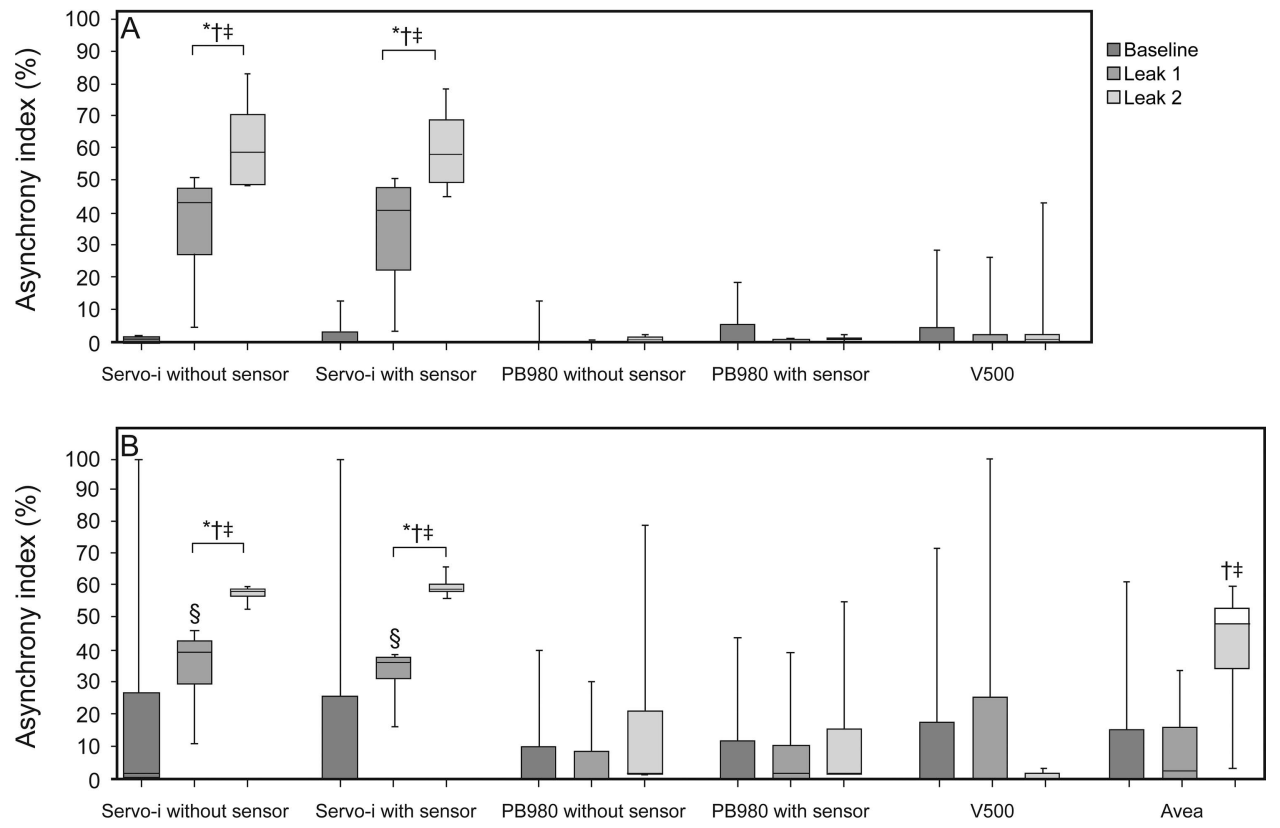

Fig. 3. Asynchrony index (\%) during volume-targeted ventilation relative to leak level. A: Volume-targeted pressure control continuous spontaneous ventilation. B: Volume-targeted pressure control continuous mandatory ventilation. Each box represents the interquartile range, with the median value shown as a horizontal line in the box. Error bars represent the maximum and minimum values. Data across all body weights were compared between ventilators at each leak level. The Servo-i and PB980 were used with and without the proximal flow sensor. ${ }^{*}=P<.05$ vs PB980, $\dagger=P<.05$ vs $\mathrm{V} 500, \ddagger=P<.05$ vs $\mathrm{PB} 840, \S=P<.05$ vs Avea; all were clinically significant $(>10 \%)$. 


\section{Leak Compensation During Neonatal Volume-Targeted Ventilation}
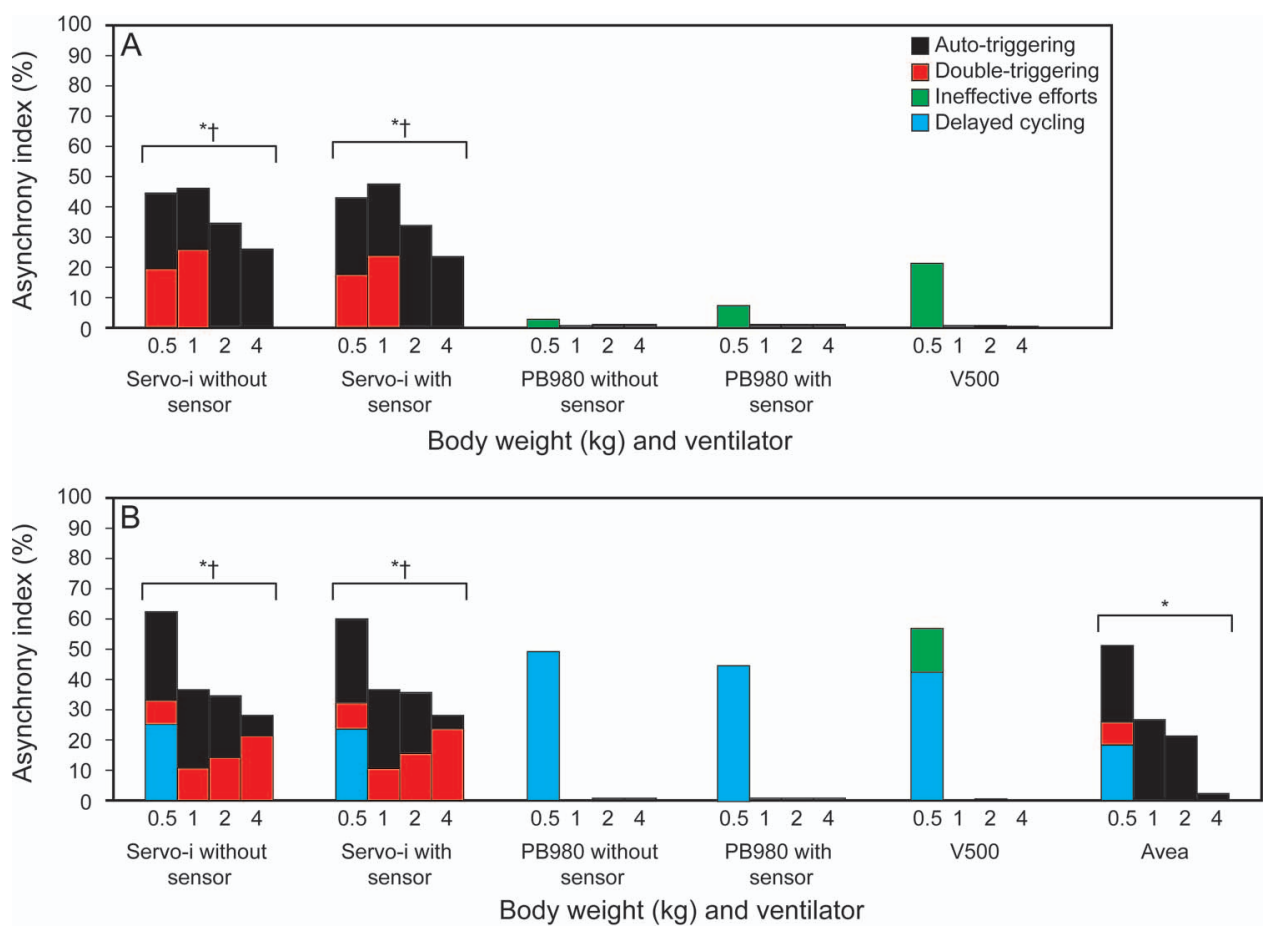

Fig. 4. The cause of asynchrony during volume-targeted ventilation and total asynchrony index. A: Volume-targeted pressure control continuous spontaneous ventilation. B: Volume-targeted pressure control continuous mandatory ventilation. The bars show total asynchrony index (\%). Each asynchrony type across all body weights and leak levels was compared. The Servo-i and PB980 were used with and without the proximal flow sensor. A: ${ }^{*} P=<.001$ vs V500 for auto-triggering, $\dagger=\mathrm{P}<.001$ vs PB980 without sensor for doubletriggering; clinically significant $(>10 \%)$. B: * $=P<.05$ vs V500 for auto-triggering, $\ddagger=P<.001$ vs PB980 without sensor for doubletriggering; clinically significant $(>10 \%)$. Each asynchrony was compared with the lowest percentage for that type of asynchrony.

minimal with the PB980 and V500; (3) with the Servo-i, baseline $\mathrm{V}_{\mathrm{T}}$ was $\geq 10 \%$ greater than set values during PC-CSV, and markedly changed with leak; (4) with the Avea, leak significantly affected delivered $\mathrm{V}_{\mathrm{T}}$ accuracy, resulting in persistent volume overshooting; (5) the PB980 and V500 showed significantly lower asynchrony index than the Servo-i during volume-targeted PC-CSV and PC$\mathrm{CMV}$; (6) auto-triggering and delayed cycling were the most common causes of asynchrony during volume-targeted PC-CSV and PC-CMV, respectively; and (7) the use of a proximal flow sensor did not affect $\Delta \mathrm{V}_{\mathrm{T}}$, asynchrony index, or type of asynchrony.

\section{The Accuracy of Delivered $V_{T}$}

Previously, Jaecklin et al ${ }^{37}$ evaluated in their neonatal bench study whether volume-targeted ventilation can deliver a constant $\mathrm{V}_{\mathrm{T}}$ following sudden changes in compliance and resistance of the respiratory system and system leak. In this study, they observed volume overshooting after a rapid increase in compliance or decrease in resistance. However, changes in delivered $\mathrm{V}_{\mathrm{T}}$ after a change in leak were minor in all tested neonatal ventilators. The reason why this result is inconsistent with our findings can be explained by some differences in study conditions. First, they switched off automatic leak compensation because of inconsistent breath-to-breath variation in delivered $\mathrm{V}_{\mathrm{T}}$ and peak inspiratory pressure, which we did not observe. Second, they used smaller leak changes of $20-30 \%$ than those of our study (about 50-100\%). High leak level was enough for the Servo-i and Avea to demonstrate frequent asynchronous events even if leak compensation was activated. A sudden drop of $\mathrm{V}_{\mathrm{T}}$ caused by ineffective efforts or an increase in $\mathrm{V}_{\mathrm{T}}$ caused by double-triggering could not be handled by volume-targeted ventilation because its algorithm limits the pressure increment from one breath to the next to a maximum of $3 \mathrm{~cm} \mathrm{H}_{2} \mathrm{O}$ to avoid overcorrection leading to excessive $\mathrm{V}_{\mathrm{T}}$ and oscillations of the system. ${ }^{2,3}$

We observed significant volume overshooting during baseline (no leak) in all Servo-i runs during PC-CSV regardless of the use of a proximal flow sensor. Contrary to this, Jaecklin et $\mathrm{al}^{37}$ during PC-CMV observed $\mathrm{V}_{\mathrm{T}}$ smaller than set values during baseline (no leak) with the Servo-i. Differences in the airway pressure waveforms at the same volume-targeted ventilation settings are supposed to be the reason for variable delivered $\mathrm{V}_{\mathrm{T}} \cdot{ }^{38}$ Although it is unclear whether concurrent use of leak compensation or a difference in the $\mathrm{V}_{\mathrm{T}}$ monitoring caused this discrepancy, further 


\section{Leak Compensation During Neonatal Volume-Targeted Ventilation}

investigations and improvements of the algorithms are needed, since prevention of hyperventilation is one of the chief goals of volume-targeted ventilation. ${ }^{1,4-6} \mathrm{We}$ observed an improvement in accuracy of delivered $\mathrm{V}_{\mathrm{T}}$ by adding leak, especially when volume-overshooting at the baseline leak and inadequate leak compensation coexisted (eg, $2 \mathrm{~kg}$ scenario with the Servo-i $[+]$ during PC-CSV). It may be possible that focusing only on delivered $\mathrm{V}_{\mathrm{T}}$ during volume-targeted ventilation makes the ability of leak compensation in each ventilator difficult to predict.

On the other hand, with the PB980 and V500, $\Delta \mathrm{V}_{\mathrm{T}}$ remained within $\pm 10 \%$ in all tested conditions, not only when leak volume was $50 \%$ but also at $100 \%$. The ventilators that we evaluated had a greater capacity to compensate for leaks, and volume-targeted ventilation continued to operate appropriately.

\section{The Incidence of Asynchrony}

To our knowledge, this is the first study to assess leak compensation algorithms during neonatal volume-targeted ventilation in terms of prevention of asynchronous events. Vignaux et al clinically investigated asynchronous events in infants and children and reported asynchrony index of $24 \%$ in invasive PC-CSV ${ }^{34}$ and $40 \%$ in noninvasive PC$\mathrm{CSV}^{35}$ even after adjustment of the termination criteria. In our previous neonatal bench study, ${ }^{14}$ we observed an asynchrony index of $29 \%$ during conventional PC-CSV and PC-CMV and observed that the asynchrony index was significantly lower with the PB980 (1\%) and V500 (3\%) than with the Servo-i (50\%) and Avea (56\%). Although we studied different modes, we observed similar frequency of asynchrony (40\% asynchrony index with the Servo-i). In view of the fact that an asynchrony index $>10 \%$ has been considered severe in previous studies, ${ }^{7,34,35}$ the appropriateness of neonatal patient-triggered modes including volume-targeted ventilation on some ICU ventilators must be questioned even if leak compensation is used concurrently.

\section{Cause of Asynchrony}

Generally, in PC-CSV, a large ETT leak may not allow the patient to flow-cycle to exhalation. ${ }^{39}$ However, delayed cycling was not seen during PC-CSV regardless of the presence of leak once we adjusted the termination criteria at baseline to ensure that the ventilator and simulator ended inspiration at the same time. This suggests that variable flow of all ventilators could match up with the leaks enough to achieve flow-cycling. On the other hand, we used fixed inspiratory times for the ventilator equal to that of the simulator in PC-CMV; thus, the timing of cycle-off criteria being met resulted in delayed cycling in the smallest infant scenarios, which have been shown to have a prolonged trigger delay time. ${ }^{28,40}$ This suggests that we may need to pay extra attention to the inspiratory time setting to avoid cycling asynchrony in premature time-cycled ventilation and that volume-targeted PC-CSV may be a better choice than volume-targeted PC-CMV.

Leak has been shown to be a major factor leading to auto-triggering, $, 8,9,28$ as we observed during PC-CSV. However, the frequency of auto-triggering did not increase in proportion to the leak level in PC-CSV. This is consistent with a previous clinical study, which demonstrated that auto-triggering occurs regardless of the leak volume, once leak flow reaches the trigger threshold. ${ }^{40}$ In PC-CMV, we observed double-triggering more often than auto-triggering at high leak level. Auto-triggered breaths were cycled in the middle of the lung model's inspiration, which resulted in a second triggering. With high leak level, autotriggered breaths started even before the start of the patient's inspiration, which may result in more frequent double-triggering.

\section{Effects of Proximal Flow Sensor}

We did not observe a significant effect of the proximal flow sensor on $\Delta \mathrm{V}_{\mathrm{T}}$ with the PB980. If an internal flow sensor can measure leak volume as accurately as a proximal flow sensor at the same leak level, the same compensation will be applied, and $\Delta \mathrm{V}_{\mathrm{T}}$ may not change. It was difficult to evaluate the effect of the proximal flow sensor on $\Delta \mathrm{V}_{\mathrm{T}}$ with the Servo-i due to high asynchrony index during the leaks tested. Rapidly developing leaks may require a few breaths before full compensation; thus, the potential of auto-triggering before compensation is maximized. Patient-ventilator synchrony significantly changes delivered $\mathrm{V}_{\mathrm{T}}$, which may be a reason why a leak level $<50 \%$ is suggested during volume-targeted ventilation. ${ }^{2-4}$

\section{Limitations}

There are several limitations to this study. First, this study was not conducted on patients, which raises the question of whether the findings are clinically important. However, it is impossible to control the level of leak in neonatal ventilation, and bench studies using the ASL 5000 ensure the same experimental condition for each ventilator. Second, parameters of our lung models potentially may not fit all patients with these body weights. Especially in children, morbid lung mechanics of patients with the same body weight generally differ and depend on their conditions. ${ }^{16,28-31}$ Third, a single-compartment model in the ASL 5000 was used. The ASL 5000 allows simulated non-linear resistance only in the dual-compartment model; thus, our lung models had linear resistance. This may affect the response of the tested ventilators in infants, since infants with lung disease frequently have non-linear resistance. ${ }^{41}$ Fourth, we tested only a limited higher range of 


\section{Leak Compensation During Neonatal Volume-Targeted Ventilation}

leaks and ventilator settings. However, we intended to evaluate the maximum capabilities of leak compensation during volume-targeted ventilation for each ventilator by selecting leak volumes that were large but also likely to be encountered in clinical settings. Fifth, we do not know whether there are any inappropriate interactions between the volume-targeted ventilation algorithm and the leak compensation algorithm. Further studies to compare volumetargeted ventilation with and without leak compensation may reveal how much improvement can be obtained in each ventilator when leak compensation is activated. Finally, we did not record $\mathrm{V}_{\mathrm{T}}$ displayed by the ventilators; thus, it is impossible to determine how much underestimation of $\mathrm{V}_{\mathrm{T}}$ is commonly seen by critical caregivers ${ }^{2-4}$ during volume-targeted ventilation under the conditions we simulated. We focused on delivered $\mathrm{V}_{\mathrm{T}}$ because it is the determinant of patients' outcome related to volumetargeted ventilation. ${ }^{1,4-6}$

\section{Conclusions}

We observed a huge variation in the capability of leak compensation among all tested ventilators during neonatal volume-targeted ventilation in terms of both prevention of asynchronous events and delivering preset $\mathrm{V}_{\mathrm{T}}$. Clinicians should be aware of these differences among ICU ventilators when they use these ventilators for neonatal volumetargeted ventilation. The PB980 and V500 were the only ventilators to acclimate to all leak scenarios. Clinical investigation is needed to validate our findings during the combination of leak compensation and neonatal volumetargeted ventilation.

\section{REFERENCES}

1. Peng W, Zhu H, Shi H, Liu E. Volume-targeted ventilation is more suitable than pressure-limited ventilation for preterm infants: a systematic review and meta-analysis. Arch Dis Child Fetal Neonatal Ed 2014;99(2):F158-F165.

2. Keszler M, Abubakar K. Volume Guarantee Ventilation. Clin Perinatol 2007;34(1):107-116, vii.

3. Keszler M. Clinical guidelines for the use of volume guarantee: practice guidelines for the bedside. Clin Perinatol 2007;34(1):116e1$116 \mathrm{e} 4$.

4. Klingenberg C, Wheeler KI, Davis PG, Morley CJ. A practical guide to neonatal volume guarantee ventilation. J Perinatol 2011;31(9): 575-585.

5. Wheeler KI, Klingenberg C, Morley CJ, Davis PG. Volume-targeted versus pressure-limited ventilation for preterm infants: a systematic review and meta-analysis. Neonatology 2011;100(3):219-227.

6. Wheeler K, Klingenberg C, McCallion N, Morley CJ, Davis PG. Volume-targeted versus pressure limited ventilation in the neonate. Cochrane Database Syst Rev 2010;(11):CD003666.

7. Thille AW, Rodriguez P, Cabello B, Lellouche F, Brochard L. Patient-ventilator asynchrony during assisted mechanical ventilation. Intensive Care Med 2006;32(10):1515-1522.
8. Carteaux G, Lyazidi A, Cordoba-Izquierdo A, Vignaux L, Jolliet P, Thille AW, et al. Patient-ventilator asynchrony during noninvasive ventilation: a bench and clinical study. Chest 2012;142(2):367-376.

9. Tobin MJ, Jubran A, Laghi F. Patient-ventilator interaction. Am J Respir Crit Care Med 2001;163(5):1059-1063.

10. Nava S, Bruschi C, Fracchia C, Braschi A, Rubini F. Patient ventilator interaction and inspiratory effort during pressure support ventilation in patients with different pathologies. Eur Respir J 1997; 10(1):177-183.

11. Tokioka H, Tanaka T, Ishizu T, Fukushima T, Iwaki T, Nakamura Y, Kosogabe $Y$. The effect of breath termination criterion on breathing patterns and the work of breathing during pressure support ventilation. Anesth Analg 2001;92(1):161-165.

12. Oto J, Chenelle CT, Marchese AD, Kacmarek RM. A comparison of leak compensation in acute care ventilators during non-invasive and invasive ventilation: a lung model study. Respir Care 2013;58(12): 2027-2037.

13. Oto J, Chenelle CT, Marchese AD, Kacmarek RM. A comparison of leak compensation during pediatric noninvasive ventilation: a lung model study. Respir Care 2014;59(2):241-251.

14. Itagaki T, Chenelle CT, Bennett DJ, Fisher DF, Kacmarek RM. Effects of leak compensation on patient-ventilator synchrony during premature/neonatal invasive and noninvasive ventilation: a lung model study. Respir Care 2017;62(1):22-33.

15. Marchese AD, Chipman D, de la Oliva P, Kacmarek RM. Adult ICU ventilators to provide neonatal ventilation: a lung model study. Intensive Care Med 2009;35(4):631-638.

16. Vignaux L, Piquilloud L, Tourneux P, Jolliet P, Rimensberger PC. Neonatal and adult ICU ventilators to provide ventilation in neonates, infants, and children: a bench model study. Respir Care 2014; 59(10): 1463-1475.

17. Iyer NP, Chatburn R. Evaluation of a nasal cannula in noninvasive ventilation using a lung simulator. Respir Care 2015;60(4):508-512.

18. Sivieri EM, Gerdes JS, Abbasi S. Effect of HFNC flow rate, cannula size, and nares diameter on generated airway pressures: an in vitro study. Pediatr Pulmonol 2013;48(5):506-514.

19. Volsko TA, Fedor K, Amadei J, Chatburn RL. High flow through a nasal cannula and CPAP effect in a simulated infant model. Respir Care 2011;56(12):1893-1900.

20. Gappa M, Pillow JJ, Allen J, Mayer O, Stocks J. Lung function tests in neonates and infants with chronic lung disease: lung and chestwall mechanics. Pediatr Pulmonol 2006;41(4):291-317.

21. Snepvangers Y, de Winter JP, Burger H, Brouwers H, van der Ent CK. Respiratory outcome in preterm ventilated infants: importance of early respiratory system resistance. Eur J Pediatr 2004;163(7): 378-384.

22. Lui K, Lloyd J, Ang E, Rynn M, Gupta JM. Early changes in respiratory compliance and resistance during the development of bronchopulmonary dysplasia in the era of surfactant therapy. Pediatr Pulmonol 2000;30(4):282-290.

23. Baraldi E, Filippone M, Trevisanuto D, Zanardo V, Zacchello F. Pulmonary function until two years of life in infants with bronchopulmonary dysplasia. Am J Respir Crit Care Med 1997;155(1):149155.

24. Bhat RY, Leipälä JA, Singh NR, Rafferty GF, Hannam S, Greenough A. Effect of posture on oxygenation, lung volume, and respiratory mechanics in premature infants studied before discharge. Pediatrics 2003;112(1 Pt 1):29-32.

25. Brar G, Geiss D, Brion LP, Rios A. Respiratory mechanics in very low birth weight infants during continuous versus intermittent gavage feeds. Pediatr Pulmonol 2001;32(6):442-446.

26. Schmalisch G, Wilitzki S, Roehr CC, Proquitté H, Bührer C. Differential effects of immaturity and neonatal lung disease on the lung 


\section{Leak Compensation During Neonatal Volume-Targeted Ventilation}

function of very low birth weight infants at 48-52 postconceptional weeks. Pediatr Pulmonol 2013;48(12):1214-1223.

27. Fauroux B, Leroux K, Desmarais G, Isabey D, Clément A, Lofaso F, Louis B. Performance of ventilators for noninvasive positive-pressure ventilation in children. Eur Respir J 2008;31(6):1300-1307.

28. Harikumar G, Moxham J, Greenough A, Rafferty GF. Measurement of maximal inspiratory pressure in ventilated children. Pediatr Pulmonol 2008;43(11):1085-1091.

29. Curzi-Dascalova L, Peirano P, Morel-Kahn F. Development of sleep states in normal premature and full-term newborns. Dev Psychobiol 1988;21(5):431-444.

30. Kapasi M, Fujino Y, Kirmse M, Catlin EA, Kacmarek RM. Effort and work of breathing in neonates during assisted patient-triggered ventilation. Pediatr Crit Care Med 2001;2(1):9-16.

31. Gerhardt T, Hehre D, Feller R, Reifenberg L, Bancalari E. Pulmonary mechanics in normal infants and young children during first 5 years of life. Pediatr Pulmonol 1987;3(5):309-316.

32. Bernstein G, Knodel E, Heldt GP. Airway leak size in neonates and autocycling of three flow-triggered ventilators. Crit Care Med 1995; 23(10):1739-1744.

33. Mahmoud RA, Proquitté H, Fawzy N, Bührer C, Schmalisch G. Tracheal tube airleak in clinical practice and impact on tidal volume measurement in ventilated neonates. Pediatr Crit Care Med 2011; 12(2):197-202.

34. Vignaux L, Grazioli S, Piquilloud L, Bochaton N, Karam O, Jaecklin $\mathrm{T}$, et al. Optimizing patient-ventilator synchrony during invasive ventilator assist in children and infants remains a difficult task. Pediatr Crit Care Med 2013;14(7):e316-e325.

35. Vignaux L, Grazioli S, Piquilloud L, Bochaton N, Karam O, Levy-Jamet $\mathrm{Y}$, et al. Patient-ventilator asynchrony during noninvasive pressure support ventilation and neurally adjusted ventilatory assist in infants and children. Pediatr Crit Care Med 2013; 14(8):e357-e364

36. Vignaux L, Vargas F, Roeseler J, Tassaux D, Thille AW, Kossowsky MP, et al. Patient-ventilator asynchrony during non-invasive ventilation for acute respiratory failure: a multicenter study. Intensive Care Med 2009;35(5):840-846.

37. Jaecklin T, Morel DR, Rimensberger PC. Volume-targeted modes of modern neonatal ventilators: how stable is the delivered tidal volume? Intensive Care Med 2007;33(2):326-335.

38. Sharma A, Milner AD, Greenough A. Performance of neonatal ventilators in volume targeted ventilation mode. Acta Paediatr 2007; 96(2):176-180

39. Brown MK, DiBlasi RM. Mechanical ventilation of the premature neonate. Respir Care 2011;56(9):1298-1311; discussion 1311-1313.

40. Ferreira JC, Chipman DW, Hill NS, Kacmarek RM. Bilevel vs ICU ventilators providing noninvasive ventilation: effect of system leaks: a COPD lung model comparison. Chest 2009;136(2):448-456.

41. Nikischin W, Gerhardt T, Everett R, Bancalari E. A new method to analyze lung compliance when pressure-volume relationship is nonlinear. Am J Respir Crit Care Med 1998;158(4):1052-1060.

This article is approved for Continuing Respiratory Care Education credit. For information and to obtain your CRCE

(free to AARC members) visit

www.rcjournal.com

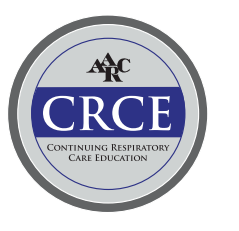

